\section{Entomological Studies on the Mosquito Borne Diseases in Iran: An Up-To-Date}

\section{Abstract}

Mosquitoes are insects that bit animal hosts to get blood as the nutrient source to develop their eggs. They may transmit a wide range of pathogens such as viruses and parasites to the hosts' body through their blood meal. It may lead to a number of mosquito-borne diseases. In Iran, there is a major risk for mosquito-borne diseases due to the introducing the exotic mosquito species from the neighboring countries. Recently, in neighboring countries of Iran, epidemics of mosquito-borne viral infections including chikungunya, dengue and West Nile infections in Pakistan, dengue and Rift Valley fever in Saudi Arabia, and West Nile infection in Iraq have been reported. Ae. albopictus has become a significant pest mosquito species in Pakistan and has also been reported from Syria, Lebanon and Turkey. According to the World Health Organization WHO, malaria is in the pre-elimination stage in Iran. In this review, it was attempted to discuss some issue including mosquito bionomics, mosquito-borne diseases in human and surveillance. Mosquitoborne disease in Iran including historically reported diseases, emerging infectious diseases as well as the mosquito fauna of Iran were also reviewed.

Keywords: Mosquito-borne diseases; Emerging infectious diseases; Iran

Received: April 29, 2019; Accepted: May 08, 2019; Published: May 15, 2019

\section{Shirzadi $\mathrm{MR}^{1,2^{*}}$}

\section{Center for Research of Endemic Parasites of Iran (CREPI), Tehran University of Medical Science, Tehran, Iran \\ 2 Center for Communicable Diseases Control, Ministry of Health and Medical Education, Tehran, Iran}

\section{*Corresponding author: \\ Dr. Mohammad Reza Shirzadi}

” shirzadim@gmail.com

Center for Communicable Diseases Control, Ministry of Health and Medical Education, Eyvanak St. Shahrak Gharb, Tehran, Iran.

Tel: +989121455413

Citation: Shirzadi MR (2019) Entomological Studies on the Mosquito Borne Diseases in Iran: An Up-To-Date. Insights Biomed Vol.4 No.2:10

\section{Introduction}

Mosquitoes are insects that bit animal hosts to get blood as the nutrient source to develop their eggs. They may transmit a wide range of pathogens such as viruses and parasites to the hosts' body through their blood meal. It may lead to a number of mosquito-borne diseases. Such diseases may be related to particular environmental conditions [1]. In 1877, the capacity of the agent of human lymphatic filariasis (Wuchereria bancrofti worm) to develop in mosquitoes was proven. In 1898, the evidence of the ability of Anopheles mosquitoes to transmit the agent of malaria (plasmodium) to humans was obtained. In 1900, Aedes aegypti was proved to transfer yellow fever [1,2].

The entrance of an exotic mosquito species into a new place is an important issue leading to spreading out of the mosquito. For example, during the last three decades, the worldwide expansion of the mosquito Aedes albopictus (the Asian tiger mosquito) from Asia to other continents was resulted in the insect establishing in the North, Central and South America, Africa, southern Europe, Oceania and the Middle East [3].

In Iran, there is a major risk for mosquito-borne diseases due to introducing the exotic mosquito species from the neighboring countries. Recently, in neighboring countries of Iran, epidemics of mosquito-borne viral infections including chikungunya, dengue and West Nile infections in Pakistan, dengue and Rift Valley fever in Saudi Arabia, and West Nile infection in Iraq have been reported [4-6]. Ae. albopictus has become a significant pest mosquito species in Pakistan and has also been reported from Syria, Lebanon and Turkey [7-9].

\section{Literature Review}

According to the World Health Organization (WHO), malaria is in the pre-elimination stage in Iran [10]. According to a report of the Ministry of Health officials, 3016 malaria cases have been identified in Iran in 2009 [11]. A half of these cases were immigrants or refugees from neighboring countries. Currently, there are three endemic malaria areas in Iran including Hormozgan, Kerman, and Sistan-Baluchistan providences with $90 \%$ of malaria cases $[10,12]$.

\section{Mosquito bionomics}

All mosquitoes belong to Nematocera suborder and categorized as the Culicidae family (dipterans). Near 42 genera of Culicidae including 3,200 species and subspecies are known $[13,14]$. The description of the composition of the Culicidae fauna in a specific 
region is not always easy due to the existence of morphologically alike and hardly detectable sibling species [15].

The host preference is a significant feature of mosquitoes. In this aspect, mosquitoes can bait various or preferentially a specific group of animals including birds or mammals [14]. The host preference powerfully affects the vector capacity of the species [16]. Some mosquitoes have a high preference for one host only. For example, $A$. aegypti, a yellow fever mosquito, has a high preference for human beings $[14,17,18]$.

Culicidae have high adaptability to various environments. The larvae (immature stages) are aquatic living in fresh or brackish water. They are able of breeding in different aquatic media $[13,14,19,20]$. Mosquito larval stage may choose edges with minimal running water to provide shelter $[13,14]$. Via accessing the aquatic surface, the Culicidae larvae can breathe atmospheric air. Larvae nourish on water microorganisms, algae, and detritus and after three molts, they convert pupae. The larval stage may endure in an overwintering mode $[13,15]$.

Adults nourish on sugary fluids such as nectar, vegetative materials, spoiled fruits and honey droplets [21]. Only the females require a blood meal to develop their eggs. Some Culicidae such as Anopheles and Culex species overwinter as adults that can prepare situation for overwintering of pathogens via the infected female vectors. Other species such as Aedes genus produce diapausing eggs that endure in the harsh season letting the overwintering of pathogens $[13,14,15]$.

Some studies have investigated bionomics of Culicidae in some regions in Iran. In 2018, Nejati et al. investigated some ecological and bionomical properties of Anopheles subpictus Grassi in southeastern Iran [22]. In parts of Asia, the mentioned species may be a secondary vector of malaria. Authors investigated the temporal forms of abundance, blood feeding action, resting behavior, host selection and larval habitats were determined. Their results showed exophilic resting behavior. Only 25 percent of engorged females confirmed positive for human blood, though most of the specimens were collected from homes. The host seeking action of the mosquito was bimodal with peaks at 22$2300 \mathrm{~h}$ and $03-0400 \mathrm{~h}$ and the relative abundance presented peaks in March and December [22]. In 2006, Vatandoost et al. illustrated bionomics of Anopheles stephensi Liston as a significant malaria vector and the most widespread anopheline mosquito in Hormozgan province, Iran [23]. The authors reported that the mosquito displays two annual activity peaks (in spring and autumn seasons). The second peak begins earlier in mountainous regions compared to coastal areas. Larvae are observed in different habitats including natural and man-made environments. Three biological subspecies of the mosquito including An. stephensi stephensi, An. stephensi mysorensis, and an intermediate form, appear in the province.

An. stephensi stephensi (type form) and intermediate form were reported from the urban- coastal areas and the rural plains and An. stephensi mysorensis occurs only in rural- mountainous regions. The presence of the malaria vector in urban and rural areas was consistent with the existing epidemiological records for malaria in the province. These outcomes may be significant for the comprehension of the epidemiology and control of malaria in the province [23].

\section{Mosquito-borne diseases in human}

Mosquitoes transmit the most broadly spread of vector-borne diseases. Malaria, a well-known mosquito-borne disease, is the greatest cause of death in human and is caused by Plasmodium parasites. Plasmodium falciparum, Plasmodium ovale, Plasmodium malariae, and Plasmodium vivax are the species of Plasmodium causing malaria in human beings and circulate between the vector and humans [13].

Lymphatic filariasis is transmitted by mosquitoes and caused by some species of nematode [24]. Mosquitoes were also reported to play a role in the transmission of tularemia, a disease caused by the bacterium Francisella tularensis [25]. Arboviruses include a variety of viruses that belong to different families and do not have a taxonomic relationship. However, they have an epidemiological importance. Mosquitoes transmit many arboviruses that cause systemic febrile disease, hemorrhagic fever, polyarthralgia, and encephalitis [13].

Genus Flavivirus includes some pathogenic arboviruses provoking hemorrhagic fevers or encephalitis and is transmitted via mosquito. Flaviviruses cause two of the major world diseases, yellow fever and dengue [26]. Principally, mosquito Ae. aegypti transmits both diseases and Ae. albopictus plays a secondary role in dengue transmission [27]. Other flaviviral diseases are West Nile virus, St Louis encephalitis, e Rocio encephalitis, and Murray Valley encephalitis [27]. Zika virus is an emerging flavivirus [13].

Among arboviruses, Alphavirus genus causes some diseases such as hemorrhagic fever, arthritis, and encephalitis [28]. One of the main emerging pathogens is Chikungunya virus that causes outbreaks of infections worldwide [29]. The O'nyong-nyong virus is a closely associated virus to Chikungunya circulates in Africa. The virus is transmitted by Anopheles mosquitoes and cause encephalitis [13]. Other alphaviruses are the Sindbis virus, Ross River virus and Barmath Forest virus [13]. A number of arboviruses belong to the Orthobunyavirus genus. Orthobunyaviruses provoke febrile disease in humans, and diagnosis of them is related to human functions e.g. mining, deforestation, urbanization, dam and highway construction [30].

\section{Mosquito-borne disease in Iran}

Historically reported diseases: Malaria is considered a historically described mosquito-borne disease in Iran [10]. Iran is endemic for malaria, but no precise information is available about frequency of the disease in Iran during previous centuries. A historical background of malaria in Iran was reviewed by Azizi and Bahadori in 2013 [10].

The malaria profile is more informative during the 19th and 20th centuries. Malaria was a main health issue in Iran during the 1796-1925. Especially, in the Caspian Sea in Gilan, Mazandaran and Gorgan provinces, it was an endemic disease. The Persian Gulf regions were also highly affected [31].

Now-a-days, malaria in Iran is in a pre-elimination phase according to the WHO [32]. For instance, 3016 cases of malaria 
Table 1 Published studies reporting laboratory screening of field-collected mosquitoes in Iran.

\begin{tabular}{|c|c|c|c|}
\hline Location & Number of Collected Specimens & Results & References \\
\hline $\begin{array}{c}\text { Firouzabad County, Fars } \\
\text { Province, Southwest of } \\
\text { Iran }\end{array}$ & 689 adults and 1313 larvae & $\begin{array}{l}3 \text { genera and } 6 \text { species of } \\
\text { Culicidae were recognized, } \\
\text { namely, Anopheles d'thali, } \\
\text { Culex sinaiticus, Culex theileri, } \\
\text { Culex mimeticus, and Culiseta } \\
\text { longiareolata. Cx. theileri was } \\
\text { the most frequent Culicidae } \\
\text { collected at Firouzabad, with a } \\
\text { total of } 613 \text { and } 247 \text { larval and } \\
\text { adult specimens, respectively }\end{array}$ & [47] \\
\hline $\begin{array}{l}\text { West Azerbaijan Province, } \\
\text { Northwestern Iran }\end{array}$ & 1336 larvae and 233 adults & $\begin{array}{l}\text { Five genera along with } 12 \\
\text { species were collected and } \\
\text { identified including: Anopheles } \\
\text { claviger, An. maculipennis s.I., } \\
\text { An. superpictus, Culex pipiens, } \\
\text { Cx. theileri, Cx. modestus, } \\
\text { Cx.hortensis, Cx. mimeticus, } \\
\text { Culiseta Longiareolata, } \\
\text { Ochlerotatus caspius s.I., Oc. } \\
\text { geniculatus and Uranotaenia } \\
\text { unguiculata. This is the first } \\
\text { record of Oc. geniculatus in the } \\
\text { province. }\end{array}$ & [48] \\
\hline $\begin{array}{l}\text { Aligudarz County, Luristan } \\
\text { province, western Iran }\end{array}$ & 96203 rd and 4th instar larva & $\begin{array}{l}\text { were captured, which } \\
\text { belonged to the following } \\
\text { species: Anopheles stephensi, } \\
\text { Anopheles d'thali, Anopheles } \\
\text { apoci, Anopheles superpictus } \\
\text { (forms A and B), Anopheles } \\
\text { marterii sogdianus, Anopheles } \\
\text { turkhodi, Anopheles } \\
\text { maculipennis S.L and }\end{array}$ & [49] \\
\hline
\end{tabular}

have been detected in Iran in 2009. A 50 percent of these patients were immigrants or refugees from neighboring countries [33]. At present, three endemic providences including Hormozgan, Kerman, and Sistan-Baluchistan have most reported cases of malaria (90 percent) in Iran [34].

Emerging infectious diseases in Iran: In order to control mosquitoborne diseases, emerging infectious diseases may be pointed out. Emerging infectious diseases develop for the first time in a given population, a defined region or the world. They may also already exist but would develop with a different pathogenesis or resistance to existing antibiotics [35].

In 2008, the first case of dengue fever was reported in Iran [36]. The case was a patient that had previously travelled to Malaysia. In a study conducted from 2000 to 2012, among 300 Iranian patients tested negative for CCHFV, $5 \%$ were serologically or molecularly positive for dengue fever [37]. Most of the positive cases were people that previously had travelled to endemic countries including Malaysia, Thailand and India. In another study, blood donors were investigated in Sistan-Baluchistan province in southeastern Iran for dengue virus. Near six percent of all subjects were serologically positive for dengue virus [38].
West Nile fever: West Nile virus is the most prevalent Flavivirus that causes West Nile fever, a mosquito-borne disease [39]. West Nile virus is widespread in Africa, America, south of Europe, Australia and Asia. The virus has been reported in some neighboring countries of Iran [40].

In the 1970s, in some provinces of Iran, the presence of West Nile virus antibody in human populations was revealed via serological analysis [41]. Migratory wild birds of the wetlands in various regions of Iran were investigated for West Nile virus from 2004 to 2007 . Results showed the presence of $15 \%$ of West Nile virus antibody among them [42,43]. In a study conducted in 2010$2011,1.3$ percent of the general population and 2.8 percent of the horses were serologically positive for West Nile virus in the northern and central provinces of Iran [44].

Zika infections: In a study conducted between 2012 to 2014, adults of Culicinae species emerging in the Sistan-Baluchestan province, southeast of Iran were identified [45]. A total of 1885 mosquitoes were collected, belonging to ten species of genus Culex. Seven Aedes unilineatus were collected as the first record for Iran. The identification of this species shows its possible establishment in the southeast of Iran. Such establishment may have implications for community health e.g. Zika and dengue and needs deep surveillance and performing the adapted vector control programs in the region [45]. 


\section{Discussion}

\section{Surveillance}

Surveillance is an important instrument that aids health experts to provide necessary knowledge about the mosquitoes existing in a region. Such information is essential to find if the transmission of a pathogen can take place in the area $[2,19]$.

Environmental surveillance is appropriate to identify pathogens already existing in a region. Such surveillance is based on the rapid laboratory screening of field-collected mosquitoes. Besides, environmental surveillance can help to find other non-target viruses as well as obtain vital evidence about the existing species of mosquitoes.

Surveillance of syndromic cases is valuable for pathogens that could be imported by infected travelers. A combined method of both surveillance systems is essential to get a useful surveillance system $[2,7]$. The combination of found data and other environmental data could create good simulations that could clarify major elements including the disease development and transmission $[2,8]$. The disease surveillance may allow the quick recognition of infected subjects and the early application of control processes.

In Table 1 published studies reporting laboratory screening of field-collected mosquitoes in Iran are represented. Such environmental surveillances have been useful to detect pathogens already existing in different regions of the country.

\section{References}

1 Service MW (1978) A short history of early medical entomology. J Med Entomol 14: 603-626.

2 Calzolari M (2016) Mosquito-borne diseases in Europe: An emerging public health threat. Rep Parasitol 5: 1-2.

3 Doosti S, Yaghoobi-Ershadi MR, Schaffner F, Moosa-Kazemi SH, Akbarzadeh K, et al. (2016) Mosquito surveillance and the first record of the invasive mosquito species Aedes (Stegomyia) albopictus (Skuse) (Diptera: Culicidae) in southern Iran. Iranian J Pub Health 45: 1064.

4 Afzal MF, Naqvi SQ, Sultan MA, Hanif A (2015) Chikungunya fever among children presenting with nonspecific febrile illness during an epidemic of dengue fever in Lahore, Pakistan. Merit Res J Med Sci 3: $69-73$.

5 Rasheed SB, Butlin RK, Boots M (2013) A review of dengue as an emerging disease in Pakistan. Public Health 127: 11-17.

6 Ali-Khan HA, Akram W, Shehzad K, Shaalan EA (2011) First report of filed evolved resis-tance to agrochemical in dengue mosquito, Aedes albopictus (Diptera: Culicidae), from Pakistan. Parasit Vectors 4: 146.

7 Hadad N, Harbach RE, Chamat S, Bouharoun-Tayoun H (2007) Presence of Aedes albopictusin Lebanon and Syria. J Am Mosa Control As-soc 23: 226-228.

8 Bonizzoni M, Gasperi G, Chen X, James AA (2013) The invasive mosquito species Aedes albopictus: Current knowledge and future perspectives. Trends Parasitol 29: 460-468.
The mosquito fauna of Iran: The mosquito fauna of Iran contains seven genera, 64 species, and three subspecies. There are 24 species in the most recent checklist of Iranian Anopheles (e.g. An. Peditaeniatus, An. fluviatilis species V, An. atroparvus, An. labranchiae, An. martinius, An. cinereus, An. nigerrimus, An. rhodesiensis rupicola). The checklist of Iranian Culicinae contains ten species of the tribe Aedini and some records of four other species including Aedes aegypti, Ochlerotatus berlandi, Oc. chelli, and Oc. dorsalis. The genus Culex includes 19 species, excluding $C x$. impudicus, and some doubtful records of $C x$. univittatus, $C x$. vishnui, and $C x$. vagans. The genus Culiseta includes five species. The genera Uranotaenia and Coquillettidia each include one species. For the An. subpictus, Oc. caspius, Oc. detritus, and Oc. pulcritaris species complexes in Iran, no data is accessible. The $C x$. pipiens and An. claviger complexes and the An. hyrcanus group need review [46-59].

\section{Conclusion}

According to the World Health Organization WHO, malaria is in the pre-elimination stage in Iran. In this review, it was attempted to discuss some issue including mosquito bionomics, mosquitoborne diseases in human and surveillance. Mosquito-borne disease in Iran including historically reported diseases, emerging infectious diseases as well as the mosquito fauna of Iran were also reviewed.

\section{Disclosure}

The author reports no conflicts of interest in this work.

9 https://www.who.int/rpc/guidelines/9789241547871/en/

10 Azizi MH, Bahadori M (2013) Brief historical perspectives of malaria in Iran. Arch Iranian Med 16: 131.

11 http://webda.behdasht.gov.ir/index.aspx?siteid=326\&pageid=3262 $8 \&$ newsview $=32293 \&$ pro=nobak

12 Moosa-Kazemi SH, Vatandoost H, Raeisi A, Akbarzadeh K (2007) Deltamethrin impregnated bed nets in a malaria control program in Chabahar, Southeast Baluchistan in Iran. Iran J Arthropod Borne Dis 1: 43-51.

13 Service MV (2001) The encyclopedia of arthropod-transmitted infections of man and domesticated animals. Wallingford, $C A B$ Publishing, USA.

14 Kettle DS (1995) Medical and veterinary entomology. (2nd edn), Wallingford, CABI Publishing, USA.

15 Busvine JR (1980) Insects and hygiene: The biology and control of insects' pests of medical and domestic importance. (3rd edn). Chapman and Hall, London, England, UK.

16 Marquardt W (2004) Biology of disease vectors. (2nd edn), Academic Press, Burlington, Canada.

17 Christopher SR (1960) Aedes aegypti (L.), the yellow fever mosquito. Cambridge University Press, London, England, UK.

18 Schaffner F, Medlock JM, Van Bortel W (2013) Public health significance of invasive mosquitoes in Europe. Clin Microbiol Infect 19: 685-692. 
19 European Centre for Disease Prevention and Control (2014) Guidelines for the surveillance of native mosquitoes in Europe. Stockholm, Sweden.

20 Becker N, Petric D, Zgomba M (2010) Mosquito and their Control. (2nd edn), Springer, Berlin, Germany.

21 Clements AN (2000) The biology of mosquitoes. Development, nutrition and reproduction. Wallingford, CABI Publishing, United States.

22 Nejati J, Saghafipour A, Vatandoost H, Moosa-Kazemi SH, Motevalli Haghi A, et al. (2018) Bionomics of Anopheles subpictus (Diptera: Culicidae) in a Malaria Endemic Area, Southeastern Iran. J Med Entomol 55: 1182-1187.

23 Vatandoost $\mathrm{H}$, Oshaghi MA, Abaie MR, Shahi M, Yaaghoobi F, et al. (2006) Bionomics of Anopheles stephensi Liston in the malarious area of Hormozgan province, southern Iran, 2002. Acta Tropica 97: 196-203.

24 http://www.who.int/mediacentre/factsheets/fs102/en/

25 Eliasson H, Broman T, Forsman M, Bäck E (2006) Tularemia: current epidemiology and disease management. Infect Dis Clin North Am 20: 289-311.

26 http://www.who.int/mediacentre/factsheets/fs100/en/

27 Sambri V, Capobianchi M, Charrel R (2013) West Nile virus in Europe: Emergence, epidemiology, diagnosis, treatment, and prevention. Clin Microbiol Infect 19: 699-704.

28 Farrar J, Hotez P, Junghanss T, Kang G, Lalloo D, et al. (2014) Manson's tropical diseases. (23rd edn), Saunders Ltd, China.

29 http://www.who.int/mediacentre/factsheets/fs327/en/

30 Vasconcelos PF, Da Rosa APT, Rodrigues SG, Da Rosa EST, Dégallier $\mathrm{N}$, et al. (2001) Inadequate management of natural ecosystem in the Brazilian Amazon region results in the emergence and reemergence of arboviruses. Cad Saude Publica 17: 155-164.

31 Edrissian GH (2006) Malaria in Iran: past and present situation. Iranian J Parasitol 1: 1-14.

32 Zoghi S, Mehrizi AA, Raeisi A, Haghdoost AA, Turki $H$, et al. (2012) Survey for asymptomatic malaria cases in low transmission settings of Iran under elimination programme. Malar J 11: 126.

33 Moosa-Kazemi SH, Vatandoost H, Raeisi A, Akbarzadeh K (2007) Deltamethrin impregnated bed nets in a malaria control program in Chabahar, Southeast Baluchistan, Iran. Iran J Arthropod Borne Dis 1: 43-51.

34 Parhizgari N, Gouya MM, Mostafavi E (2017) Emerging and reemerging infectious diseases in Iran. Iranian J Microbiol 9: 122.

35 Chinikar SGS, Moradi M, Goya MM, Shirzadi MR, Zeinali M, et al. (2010) Geographical distribution and surveillance of crimean-congo hemorrhagic fever in Iran. Vector Borne Zoonotic Dis 10: 705-708.

36 Chinikar S, Ghiasi SM, Shah-Hosseini N, Mostafavi E, Moradi $M$, et al. (2013) Preliminary study of dengue virus infection in Iran. Travel Med Infect Dis 11: 166-169.

37 Aghaie A, Aaskov J, Chinikar S, Niedrig M, Banazadeh S, et al. (2014) Frequency of dengue virus infection in blood donors in Sistan and Baluchestan province in Iran. Transfus Apher Sci 50: 59-62.
38 Garmendia AE, Van Kruiningen HJ, French RA (2001) The West Nile virus: Its recent emergence in North America. Microbes Infect 3: 223-229.

39 Lanciotti RS, Ebel GD, Deubel V, Kerst AJ, Murri S, et al. (2002) Complete genome sequences and phylogenetic analysis of West Nile virus strains isolated from the United States, Europe, and the Middle East. Virology 298: 96-105.

40 Naficy K, Saidi S (1970) Serological survey on viral antibodies in Iran. Trop Geogr Med 22: 183-188.

41 Fereidouni SR, Ziegler U, Linke S, Niedrig M, Modirrousta H, et al. (2011) West Nile virus monitoring in migrating and resident water birds in Iran: are common coots the main reservoirs of the virus in wetlands? Vector Borne Zoonotic Dis 11: 13771381.

42 Chinikar S, Shah-Hosseini N, Mostafavi E, Moradi M, Khakifirouz S, et al. (2013) Seroprevalence of West Nile virus in Iran. Vector-Borne and Zoonotic Dis 13: 586-589.

43 Mehravaran AMM, Telmadarraiy Z, Mostafavi E, Moradi AR, Khakifirouz S, et al. (2013) Molecular detection of CrimeanCongo haemorrhagic fever (CCHF) virus in ticks from southeastern Iran. Ticks Tick Borne Dis 4: 35-38.

44 Yaghoobi-Ershadi MR, Doosti S, Schaffner F, Moosa-Kazemi $\mathrm{SH}$, Akbarzadeh K, et al. (2017) Morphological studies on adult mosquitoes (Diptera: Culicidae) and first report of the potential Zika virus vector Aedes (Stegomyia) unilineatus (Theobald, 1906) in Iran. Bulletin de la Société de Pathologie Exotique 110: 116-121.

45 Azari-Hamidian S (2007) Checklist of Iranian mosquitoes (Diptera: Culicidae). J Vector Ecol 32: 235-242.

46 Soltani Z, Keshavarzi D, Ebrahimi M, Soltani A, MoemenbellahFard MJ, et al. (2017) The fauna and active season of mosquitoes in west of Fars Province, Southwest of Iran. Arch Razi Inst 72: 203-208.

47 Khoshdel-Nezamiha F, Vatandoost H, Azari-Hamidian S, Bavani MM, Dabiri F, et al. (2014) Fauna and larval habitats of mosquitoes (Diptera:Culicidae) of West Azerbaijan Province, Northwestern Iran. J Arthropod-Borne Dis 8: 163.

48 Amani H, Yaghoobi-Ershadi MR, Kassiri H (2014) The ecology and larval habitats characteristics of anopheline mosquitoes (Diptera: Culicidae) in Aligudarz County (Luristan province, western Iran). Asian Pacific J Trop Biomed 4: S233-S241.

49 Zahirnia AH, Zendehfili H (2014) Mosquito Fauna (Diptera: Culicidae) of Hamedan County, Western Iran. J ArthropodBorne Dis 8: 212.

50 Nikookar SH, Fazeli-Dinan M, Azari-Hamidian S, Mousavinasab SN, Aarabi M, et al. (2017) Correlation between mosquito larval density and their habitat physicochemical characteristics in Mazandaran Province, northern Iran. PLoS NegI Trop Dis 11: e0005835.

51 Moosa-Kazemi SH, Zahirnia AH, Sharifi F, Davari B (2015) The fauna and ecology of mosquitoes (Diptera: Culicidae) in Western Iran. J Arthropod-Borne Dis 9: 49.

52 Nikookar SH, Moosa-Kazemi SH, Yaghoobi-Ershadi MR, Vatandoost H, Oshaghi MA, et al. (2015) Fauna and larval habitat characteristics of mosquitoes in Neka County, Northern Iran. J Arthropod-Borne Dis 9: 253. 
53 Kazemi SM, Karimian F, Davari B (2010) Culicinae mosquitoes in Sanandaj county, Kurdistan province, western Iran. J Vector Borne Dis 47: 103.

54 Navidpour S, Vazirianzadeh B, Harbach R, Jahanifard E, Moravvej SA, et al. (2012) The identification of culicine mosquitoes in the Shadegan wetland in southwestern Iran. J Insect Sci 12: 1-4.

55 Saghafipour A, Abai MR, Farzinnia B, Nafar R, Ladonni H, et al. (2012) Mosquito (Diptera: culicidae) fauna of Qom province, Iran. J Arthropod-Borne Dis 6: 54

56 Hanafi-Bojd AA, Vatandoost $H$, Oshaghi MA, Charrahy $Z$, Haghdoost AA, et al. (2012) Larval habitats and biodiversity of anopheline mosquitoes (Diptera: Culicidae) in a malarious area of southern Iran. J Vector Borne Dis 49: 91.
57 Moosa-Kazemi SH, Vatandoost H, Nikookar H, Fathian M (2009) Culicinae (Diptera: culicidae) mosquitoes in chabahar County, sistan and baluchistan Province, southeastern Iran. Iranian Journal of Arthropod-borne Diseases 3: 29.

58 Zahirnia A H, Rastgar H, Azarihmidian S, Salehzadeh A (2017) Determination of mosquitoes fauna (Culicidae: Diptera) in Poldokhtar county of Lorestan province, 2015. Avicenna J Clin Med 24: 126-134.

59 Azari-Hamidian S, Joeafshani MA, Mosslem M, Rassaei AR (2005) Mosquito fauna and distribution of the genus Culex (Diptera:Culicidae) in Guilan province. Pajouhesh Sazandegi 68: 39-45. 